\title{
Imaginar España, vivir en Argentina: la inserción de los profesores exiliados republicanos en las redes intelectuales y culturales en Bahía Blanca (1956-1966)
}

\author{
To imagine Spain, to live in Argentina: the insertion of Republican exiled professors in
}

intellectual and cultural networks in Bahía Blanca (1956-1966)*

\section{Federico Martín Vitelli}

Doctorando en Historia en la Universidad Nacional del Sur fedevite20@gmail.com

\begin{abstract}
Resumen: En el presente trabajo pretendemos dar cuenta de las formas de inserción de los profesores republicanos exiliados españoles tras el estallido de la Guerra civil española y durante el primer franquismo, en las redes intelectuales y culturales de la ciudad de Bahía Blanca, entre 1956 y 1966. Desde el entrecruzamiento de las escalas local y transnacional, procuraremos abarcar íntegramente la complejidad metodológica del objeto de estudio exiliar, con el fin de exponer el grado de importancia que tuvieron las relaciones laborales, políticas asociacionistas y culturales para la integración de los profesores exiliados en los ámbitos intelectuales y universitarios bahienses; reconstruir históricamente las trayectorias de los mismos y de las instituciones en las que intervinieron $y$ verificar el impacto trasformador de sus aportes en dichas entidades.
\end{abstract}

Palabras claves: Exilio republicano español, Historia de las universidades, Intelectuales.

\begin{abstract}
In the following paper we intend to point out the ways in which the Spanish exiled professors inserted themselves, after the outbreak of the Spanish civil war and during the first Franco regime, in the intellectual and cultural networks of Bahía Blanca between 1956 and 1966. Our perspective is based on the intersection of local and transnational scales, from where we pretend to fully reach the methodological complexity of the exile studies object. Our objectives are: to expose the importance that the working, political, associationist, and cultural networks had in the integration of the exiled professors in the intellectual and universitary ambient; to rebuild historically the trajectories of the exiled and of the institutions in which they intervened; and to verify the transforming impact of their contributions in those institutions.
\end{abstract}

Key Words: Spanish republicanism exile, History of universities, Intellectuals.

\footnotetext{
* Esta investigación está financiada por una beca doctoral interna del CONICET
} 


\section{Introducción}

En el presente artículo pretendemos dar cuenta de las formas de inserción de los profesores republicanos exiliados españoles tras el estallido de la Guerra civil española y durante el primer franquismo (1939-1959), en las redes intelectuales, culturales y universitarias existentes en la ciudad de Bahía Blanca entre 1956 y 1966.

El período analizado comienza con el arribo los mismos a la ciudad para desempeñarse como docentes en la Universidad Nacional del Sur (UNS) creada en 1956. El mismo culmina en 1966, momento de la salida de la mayor parte de dichos profesores de la ciudad, producto del viraje de la política universitaria nacional tras el golpe de estado liderado por Juan Carlos Onganía ${ }^{1}$. Las prácticas represivas aplicadas por el gobierno dictatorial en el ámbito académico, determinaron que estos optaran, o bien por reubicarse en otras áreas laborales en distintas regiones argentinas, o bien por retornar a España tras la atenuación progresiva de las políticas represivas del régimen franquista ${ }^{2}$.

$\mathrm{Al}$ reducir la escala de análisis, abrevamos en los postulados de la Historia local. Siguiendo las propuestas y advertencias de Serna y Pons (2003) partimos de "lo local", no como un mero marco espacial, sino como una tipología de investigación y un posicionamiento intelectual que busca estudiar determinados problemas en la localidad. De esta forma, buscamos comprender cómo se relacionan estos aspectos con los hechos concretos, entendiendo de qué modo lo universal (en nuestro caso, la inserción de

\footnotetext{
${ }^{1}$ El General Onganía lideró el golpe de estado -autodenominado como "Revolución Argentina"- que derrocó al presidente radical Illia en 1966. La Revolución Argentina al contrario de las experiencias dictatoriales anteriores, pretendió establecerse como un nuevo sistema dictatorial de tipo permanente. Dicho período dictatorial culmina en 1973.

${ }^{2}$ Si bien la centralidad del aspecto represivo en la conformación del régimen franquista permaneció hasta la finalización del mismo, a mediados de la década de 1960 -con el aumento de la cuota de poder del sector aperturista al interior de la dictadura- se promulgaron una serie de leyes y de cambios administrativos que disminuyeron las dificultades para el acceso de exiliados a pasaportes en embajadas, ampliando los resquicios posibles para sus retornos en condiciones más seguras y para el incremento de la participación política al interior de España. Entre ellas destacamos -pese a sus resultados parciales- la aprobación de la Ley de Prensa e Imprenta de 1966, la Ley de Libertad Religiosa de 1967 y el Decretoley 10/1969 de 1969, por el que se "declara la prescripción de todos los delitos cometidos con anterioridad al 1 de abril de 1939, cualesquiera que sean sus autores, su gravedad o sus consecuencias, con independencia de su calificación y penas presuntas, y sin tener en cuenta las reglas que los Códigos vigentes establecen sobre cómputo, interrupción y reanudación de los plazos de prescripción del delito". Publicado en el Boletín Oficial del Estado del Gobierno de España. Disponible en internet en https://www.boe.es/diario_boe/txt.php?id=BOE-A-1969-392 Acceso 27 de septiembre de 2017.
} 
profesores republicanos exiliados) se expresa en lo local (las comunidades universitarias de la UNS y asociaciones culturales).

No se trata solo de acortar la escala sino de encontrar en ello nuevas preguntas, actores y temas que se escapan al uso únicamente centrado en perspectivas de alcance nacional. Esta mirada debe ser complementada con la utilización de una escala transnacional que como afirman Jensen y Lastra

ha abierto un nuevo desafío a los investigadores de los exilios políticos masivos del siglo XX, invitándolos a cambiar la lente o a jugar en otro nivel de análisis que atienda a la constitución de solidaridades colectivas, redes intelectuales internacionales, configuraciones identitarias transfronterizas, trabajos multilocales en orden a la protección universal de derechos y a la elaboración de culturas políticas supranacionales (JENSEN Y LASTRA, 2015:4).

En cuanto al concepto de redes, entendemos que la observación de los vínculos interpersonales, circunscripta hasta hace pocos años al ámbito de la sociología, se ha convertido en una herramienta adecuada para las líneas de investigación del fenómeno exiliar en perspectiva histórica. En este sentido, su uso es pertinente para analizar las migraciones intercontinentales (RAMELLA, 1995); para los estudios de microhistoria (REVEL, 1996) y para explicar de forma amplia la diversidad y complejidad de las sociedades y de la construcción del poder en su seno (SANTILLI, 2003). Resultan relevantes los progresos registrados en la conceptualización de las redes como instancias superpuestas que desbordan los límites de los Estados-nación en el estudio transnacional del exilio; en la investigación de las estructuras relacionales de origen y recepción y en el análisis de los niveles de movilidad ínter e intrageneracionales dependientes de las reconstrucciones de sus universos relacionales y simbólicos, de sus historias previas, de sus trayectorias de destino y de sus sistemas de referencia identitarios. Incluso cuando el objeto coincide con las fronteras de los Estados-nación, esta concepción nos permite recuperar para los estudios exiliares una dimensión de lo "nacional" no enquistada como una categoría dada por naturaleza sino como una construcción cultural socialmente operativa.

A su vez, entendemos al concepto de redes intelectuales como el "conjunto de personas ocupadas en los quehaceres del intelecto que se contactan, se conocen, 
intercambian trabajos, se escriben, elaboran proyectos comunes, mejoran los canales de comunicación $\mathrm{y}$, sobre todo, establecen lazos de confianza recíprocos" (DEVÉZ VALDÉZ, 2014). Este concepto enriquece las miradas realizadas desde categorías tales como "generación" o "campo", debido a que permite reconocer tanto los vínculos de solidaridad como los de competencia, al tiempo que habilita al análisis del diálogo intergeneracional entre agentes de distintas franjas etarias y con disímiles capitales relacionales y experienciales.

Nos proponemos determinar dentro del grupo de profesores exiliados arribados a Bahía Blanca a quienes, además de desarrollar tareas específicas de docencia, desempeñaron el rol de intelectuales. Entendemos que

el intelectual no es solo la persona especialmente inteligente, inclinada a la vida intelectual o especialista en el trabajo intelectual, sino que son algo así como la inteligencia pública de la sociedad civil. Las características de un intelectual están determinadas no por su capacidad, sino por su función social, que consiste en construir espejos de interés para la sociedad, para hacerla pensante, crítica, imaginativa, creadora y en movimiento. Por eso son considerados como la conciencia de la sociedad (ZAID, 1990: 21).

Es decir, que solo consideraremos como intelectuales a quienes pusieron su capital simbólico y cultural en debate en el espacio público, generando y trasmitiendo en el mismo, determinados sentidos y cosmovisiones sobre la sociedad y el mundo.

En vista a este objetivo, pretendemos recuperar sus trayectorias intelectuales para reconstruir sus formas de participación y aportes en espacios extrauniversitarios bahienses de relevante actividad cultural durante el período tales como la filial local del Colegio Libre de Estudios Superiores $(\mathrm{CLES})^{3}$ y la Asociación Bernardino Rivadavia $(\mathrm{ABR})^{4}$. Asimismo, incluiremos determinadas referencias a la participación de los

\footnotetext{
${ }^{3}$ El CLES (1931-1960) fue una institución formada por intelectuales ligados al socialismo, al antifascismo y -desde la irrupción del peronismo como movimiento político-al heterogéneo mundo del antiperonismo, que surgió en Buenos Aires extendiéndose posteriormente hacia ciudades del interior como Bahía Blanca, Rosario, Córdoba, La Plata y Mendoza. Su órgano de publicación era la revista trimestral Cursos y Conferencias donde se publicaron discursos y trabajos producidos en las distintas filiales vinculadas a lo académico, pero con un visible tinte político. En la misma publicaron numerosas veces los exiliados radicados en Bahía Blanca.

${ }^{4}$ Institución civil sin fines de lucro fundada en 1882 por vecinos nacidos en Bahía Blanca y por inmigrantes europeos con formación profesional, que en su mayoría desempeñaban una relevante participación pública local.
} 
profesores en las asociaciones étnicas de origen español y regionalista existentes en la ciudad $^{5}$, como forma de vislumbrar los alcances y las complejidades en la formación de las redes culturales e intelectuales en las que intervinieron.

En este sentido, nos planteamos los siguientes objetivos: 1. analizar la importancia que tuvieron las relaciones laborales, políticas y culturales para la integración de los profesores exiliados en los ámbitos intelectuales y asociacionistas bahienses; 2. reconstruir históricamente las trayectorias de los exiliados y de las instituciones en las que intervinieron; 3. ponderar las huellas de la interacción entre los educadores republicanos y el entramado de organizaciones culturales y societales nuevas o de larga tradición en la ciudad; y 4. valorar el impacto de la escala local en la elucidación de dinámicas exiliares analizadas a escala estatal y transnacional.

Para cumplir con estos propósitos analizamos un amplio corpus documental compuesto por: el Archivo de la UNS; documentos pertenecientes al Archivo Pablo Lejarraga $^{6}$ referidos al CLES; el Archivo General de la Guerra civil Española de Salamanca - en especial, aquellas cartas personales y documentos de los registros civiles de los profesores exiliados-; curricula vitae de los protagonistas; carteles de conferencias; los archivos de distintas asociaciones, centros y federaciones españolas y regionalistas de Bahía Blanca; el Archivo de la ABR y el de la Fundación Ezequiel Martínez Estrada ${ }^{7}$. Además, se analizaron entrevistas realizadas al grupo de docentes exiliados y testimonios de sus allegados publicados en distintos medios gráficos y digitales, así como publicaciones de divulgación académica del periodo tales como la revista Cuadernos del Sur ${ }^{8}$ producida por el Departamento de Humanidades de la UNS y Cursos y Conferencias $^{9}$ editada desde el CLES.

\footnotetext{
${ }^{5}$ Para esta etapa, el mapa asociativo español bahiense estaba conformado por la Sociedad Española de Socorros Mutuos (fundada en 1882), el Club Español (1915); la Unión Vasca "Laurak-Bat" (1899); el Centro Gallego (1916); la Casa de Galicia (1920); el Casal Catalá (1912): la Asociación Española de Socorros Mutuos (1938); el Centro Andalucía (1914); el Centro Republicano Español (1928) y la Federación Regional de Sociedades Españolas (1922) (GUARDIOLA PUBLINS, 1992:356).

${ }^{6}$ Pablo Lejarraga (1906-1989) fue un abogado y militante socialista, de ideología reformista, antifascista y antiperonista, de importante actividad en el ámbito cultural bahiense. Fue secretario de la Filial bahiense del CLES desde su fundación en 1941 hasta su cierre en 1960.

${ }^{7}$ Ezequiel Martínez Estrada (1895-1964) fue un escritor, poeta, ensayista, crítico literario y biógrafo de gran prestigio en el ámbito intelectual argentino. Recibió dos veces el Premio Nacional de Literatura, en 1933 por su obra poética y en 1937 por el ensayo "Radiografía de la Pampa". Fue presidente de la Sociedad Argentina de Escritores (SADE) de 1933 a 1934 y de 1942 a 1946.

${ }^{8}$ Revista institucional del Departamento de Humanidades de la UNS fundada en 1958. Tras ser editada de forma discontinua, logró consolidarse como un proyecto con periodicidad semestral a partir del $\mathrm{N}^{\circ} 5$ en 1966. Desde sus comienzos tuvo como objetivos difundir artículos, reseñas, notas breves, debates y/o entrevistas de distintas disciplinas realizados principalmente por alumnos y profesores de la UNS.
} 
El trabajo se estructura en dos partes. La primera corresponde a la descripción y caracterización de la inserción de los profesores republicanos exiliados durante los primeros años de la historia de la UNS cuyo surgimiento y rápido crecimiento la situó como la principal institución cultural bahiense. El segundo apartado, aborda el desenvolvimiento profesional, laboral e intelectual de los mismos en las redes locales conformadas por diversas entidades culturales como el CLES y la ABR, en vínculo con redes propias del asociacionismo español y regionalista.

\section{La inserción de los profesores exiliados en la Universidad Nacional del}

\section{Sur}

Entendemos que las universidades en tanto agencias estatales revisten una situación de excepcionalidad, al ser instituciones legalmente autónomas y cogobernadas y al mismo tiempo integrantes del "sector público estatal, determinadas por orientaciones impuestas o negociadas con los actores estatales que limitan esa pretendida autonomía de los universitarios" (FREDERIC, GRACIANO Y SOPRANO, 2010: 18). Esta doble dimensión resulta fundamental para, por un lado, no trasladar de forma mecánica la situación política nacional a la realidad universitaria, y por el otro, no entender al ámbito académico como una isla impermeable a los procesos culturales, sociales, económicos y políticos locales, nacionales y transnacionales.

La UNS se fundó en 1956 sobre la base del Instituto Tecnológico del Sur creado 10 años antes. Dicha fundación estuvo motorizada desde varios sectores, que disimiles entre sí $^{10}$, adherían de forma masiva al reclamo de instalar en la ciudad de Bahía Blanca una universidad nacional.

Los primeros años de su funcionamiento se caracterizaron por una intensa labor académica beneficiada, tanto por el trabajo interdisciplinario incentivado desde la elección de una estructura administrativa departamental, como por la llegada constante de profesores desde otras universidades, debido, entre otros factores, a la insuficiente

\footnotetext{
${ }^{9}$ Publicación de periodicidad mensual en la que se transcribían cursos y conferencias dictados por profesores e intelectuales de distintos ámbitos ligados al CLES. En las mismas se publicaron, a su vez, reseñas de las actividades realizadas en las distintas filiales, entre ellas Bahía Blanca.

${ }^{10}$ Dichos sectores constituían un arco compuesto por estudiantes, profesores, profesionales, empresarios, funcionarios, periodistas y habitantes en general, cuya ideología iba desde el conservadurismo militar y católico hasta el socialismo militante, pasando por sectores liberales y moderados.
} 
cantidad de educadores con formación pedagógica específica disponibles en el medio local y a la necesidad de cubrir los cargos docentes recién abiertos (CERNADAS, 2006: $44)$.

Dicha necesidad de cubrir cargos vacantes constituye uno de los principales problemas que debió afrontar tanto el Instituto Tecnológico del Sur como la recientemente creada universidad. Para ello, las autoridades universitarias establecieron desde 1949 una partida especial de fondos -que se mantuvo hasta fines de la década de 1950- para la contratación de formadores de otros centros académicos en el país y en el extranjero. Entre estos, se destacaron por su importante formación académica un conjunto de profesores europeos que habían abandonado sus países por la Segunda Guerra Mundial y por la Guerra civil española.

En su condición de exiliados se encontraban atravesados, en las formas de sus partida, permanencia y expectativas de retorno, por una dimensión represiva que le da origen (RONINGER, 2014). Tal como afirma Groppo

El exilio es una forma de migración que se distingue de las llamadas migraciones económicas por su carácter forzado: el exiliado es un migrante involuntario que habría deseado quedarse en su país, pero que es expulsado de él o debió dejarlo para escapar de persecuciones o amenazas graves. El objetivo de esta migración forzada es salvaguardar la vida y la libertad (GROPPO, 2002).

De esta forma, arribaron a la ciudad un grupo de siete profesores republicanos exiliados de la España franquista, con una amplia formación en sus disciplinas principalmente humanísticas- como son los casos de Nicolás Sánchez Albornoz, Alberto Vilanova Rodríguez, Fernanda Monasterio, Manuel Lamana, José Bernal Ulecia, Julio Hernández Ibáñez y Rafael Olivar Bertrand. La designación de estos bajo la categoría de republicanos refiere a la posición pública tomada por ellos en defensa del gobierno democrático encarnado en la Segunda República en clara oposición al régimen franquista. Sin embargo, los proyectos políticos de cada uno no eran idénticos entre sí, abarcando un horizonte ideológico que incluyó la filiación socialista de Hernández Ibáñez dentro del Partido Socialista Obrero Español al cual presidió; la participación en las juventudes socialistas de Bernal Ulecia; la militancia regionalista en defensa de la cultura gallega de Vilanova Rodríguez; la posición independiente y apartidaria de 
Monasterio y la adhesión a la causa republicana y nacionalista catalana de Olivar Bertrand.

La totalidad de los profesores exiliados que arribaron a Bahía Blanca, ya se encontraban establecidos en otras regiones argentinas desde la década de 1940, desempeñándose como docentes en otras universidades nacionales, tales como la Universidad Nacional de La Plata y la Universidad Nacional de Cuyo (Díaz Labajo, 2004). Esta situación se debió a que, tras la llegada al país durante el exilio masivo de 1939 o durante el posterior exilio por goteo de las décadas de 1940 y 1950, la mayoría de los mismos encontraron frecuentes dificultades para homologar sus títulos e insertarse laboralmente en Buenos Aires, tal como era su objetivo primordial, al tiempo que distintas universidades del interior implementaron políticas de atracción para contratarlos en una coyuntura marcada por la apertura de carreras y el proceso de desperonización ${ }^{11}$ a partir de 1955 (SCHWARTZSTEIN, 2001).

La política de atracción generada desde la UNS para posibilitar el arribo de estos profesores e intelectuales fue motivada mayormente por el prestigio internacional de los mismos, alcanzado por su actividad docente y de divulgación científica realizada en España antes de estallar la contienda o en los países que los albergaron durante su primer exilio. Además, fueron clave la relación personal y profesional que mantuvieron con educadores locales y españoles ya instalados en el país y el activo trabajo de las instituciones especialmente creadas para apoyar materialmente y facilitar la inserción laboral de profesores que se veían obligados a huir de sus países de origen.

Los profesionales fueron contactados por diferentes vías que incluyeron la activa participación de distintos agentes e instituciones públicas y privadas. Entre las mismas podemos destacar la actuación de organismos internacionales como la Organización Internacional para Refugiados ${ }^{12}$ de las Naciones Unidas; organismos nacionales como la

\footnotetext{
${ }^{11}$ Se denomina "desperonización" al proceso iniciado por la dictadura devenida del golpe de estado de 1955, que se propuso borrar los rastros del gobierno peronista en la sociedad argentina mediante una amplia proscripción y represión, establecida legalmente a partir del Decreto-Ley 4661. La desperonización abarco especialmente los ámbitos públicos a partir de cesantías y censuras que incluyeron al espacio educativo. La misma, tuvo lugar bajo el objetivo declarado en el Decreto-Ley 333 de 1958, en el cual se establecía "la necesidad de desmantelar estructuras totalitarias para la esencia real democrática de las instituciones argentinas".

12 La OIR fue creada en 1947 como organismo especializado de las Naciones Unidas. Su labor se circunscribió a la ayuda a refugiados europeos que abandonaron sus países de origen por la Segunda Guerra Mundial y la Guerra civil española. Intentó abordar de forma exhaustiva todos los aspectos relativos a la cuestión de los refugiados, tales como su repatriación, identificación, registro, clasificación, asistencia, protección legal y política, transporte, reasentamiento y reinserción.
} 
Institución Cultural Española $(\mathrm{ICE})^{13}$; fundaciones de capital privado como la Fundación Rockefeller -clave en el apoyo otorgado para facilitar la inserción laboral universitaria en la Universidad Nacional de Cuyo y en la UBA de Claudio Sánchez Albornoz $^{14}$ (padre de Nicolás Sánchez Albornoz) (LIDA, 2018)-; la intervención de autoridades diplomáticas argentinas en Europa y el rol desempeñado por docentes que ya se encontraban insertos en el país, los cuales procedieron a recomendar en distintas universidades la contratación de colegas que aún permanecían en Europa en situación de seria vulnerabilidad.

Los contactos realizados por educadores españoles ya instalados en nuestro país para allanar el acceso de profesores exiliados al medio universitario fueron constatados en otros estudios de casos a escala local y transnacional. Dentro de los mismos, podemos mencionar la intensa actividad realizada por el matemático Julio Rey Pastor, quien residiendo en Argentina desde 1921, apoyó a jóvenes matemáticos republicanos perseguidos por el franquismo franqueándoles las puertas de la Universidad Nacional del Litoral en Rosario (DE MARCO, 2015).

Los mediadores resultaron una pieza fundamental -en el marco de una situación de comunicaciones lentas y coyunturas personales angustiosas y urgentes- para incidir en las decisiones tomadas por distintas instituciones que pese a su predisposición no tenían una gran tradición de propiciar la inclusión de extranjeros dentro de sus filas (DÍAZ LABAJO, 2004).

Otro aspecto a tener en cuenta en el análisis de las formas de arribo al país, se refiere al conocimiento de muchos de los exiliados de su futuro destino de residencia debido a que en años anteriores habían trabajado en él. En este contexto, jugaron un papel relevante las relaciones institucionales que se desarrollaron a través de la puesta en marcha de programas que promovieron el intercambio profesional entre docentes españoles y argentinos. Dichos programas fueron ejecutados por la Junta de Ampliación de Estudios e Investigaciones Científicas (JAE), por la ICE de Buenos Aires y por

\footnotetext{
${ }^{13}$ Creada en 1914, se encargó de invitar desde entonces a su cátedra de Cultura Española a prestigiosos profesores e intelectuales españoles de la talla de José Ortega y Gasset, Julio Rey Pastor, Carles Pi i Sunyer y Pío del Río Hortega.

${ }^{14}$ Claudio Sánchez-Albornoz (1893 -1984). Fue uno de los más notables medievalistas españoles. En cuanto a su carrera política fue ministro durante la Segunda República. Después de la Guerra Civil decidió exiliarse en Argentina donde se desempeñó en distintas Universidades Nacionales. Su accionar político y cultural lejos de España lo llevo a ser presidente de la Republica en el Exilio entre los años 1962 y 1971.
} 
centros de inmigrantes creados desde la masiva llegada de españoles a la Argentina en la segunda mitad del siglo XIX, como el Centro de Gallegos de Buenos Aires. De esta forma, distintos exiliados en Argentina como Pío del Río Hortega, María de Maeztu o Claudio Sánchez Albornoz, entre otros, ya habían trabajado en el país con anterioridad a su exilio durante las décadas de 1920 y 1930 (DÍAZ LABAJO, 2010).

Para ejemplificar las trayectorias de los profesores exiliados arribados a Bahía Blanca, profundizaremos en la reconstrucción de las trayectorias de Nicolás Sánchez Albornoz (1926) y Manuel Lamana (1922-1996) quienes llegan a Argentina en 1954 tras un primer exilio en Francia. Este se produce después de haber escapado del Valle de los Caídos -un importante campo de concentración franquista también llamado "Cuelgamuros"- en donde estaban cumpliendo condena de trabajos de forzados desde 1947 (SÁNCHEZ ALBORNOZ, 2012: 110). Ese año fueron condenados a seis y cuatro años de prisión respectivamente por su intento de reconstrucción del antiguo sindicato estudiantil clandestino -la Federación Universitaria Escolar (FUE)- de carácter republicano.

Ambos exiliados motivados tanto por los efectos de la dispersión de los miembros de la FUE dentro y fuera de España, como por la insistencia de Claudio Sánchez Albornoz para que su hijo se instale en Argentina y trabaje junto a él, decidieron exiliarse nuevamente esta vez en América.

Claudio Sánchez Albornoz, se hallaba investigando y dando clases en la Universidad de Cuyo y en la Universidad de Buenos Aires desde hacía casi una década. Durante ese período había realizado numerosas gestiones para lograr la libertad de su hijo mientras estuvo preso en el Valle de los Caídos y para asegurarle la vía de ingreso al país mientras se encontraba en Francia.

Después de un breve paso como profesor en historia y geografía en el Lycée Français de Buenos Aires, Nicolás Sánchez Albornoz arribó a Bahía Blanca para desempeñarse como Profesor Titular de Historia Moderna y Medieval durante el año 1957. Acerca de su llegada a la ciudad, menciona en su autobiografía que tras la caída del gobierno peronista

los estudiantes exigieron a las autoridades designadas que los profesores nombrados a dedo por el peronismo o los de manifiesta incompetencia fueran cesados de inmediato. El expurgo parcial acometido obligó a que los interventores reclutaran reemplazantes. Cubrir las vacantes producidas no tropezó en la Universidad de Buenos Aires con demasiados inconvenientes. 
La ciudad contaba con un buen número de docentes depuestos, exiliados o de jóvenes hasta entonces vetados. En las universidades del interior, faltas de cantera propia, el reclutamiento resulto más complicado. (...] A los pocos meses el gobierno provisional fundó la Universidad Nacional del Sur con sede en la ciudad de Bahía Blanca. El destacado filósofo Vicente Fatone, facultado para ponerla en pie, operó con mano expeditiva. Creados los departamentos esenciales, sacó a concurso las materias troncales. La Universidad Nacional del Sur, menor de tamaño, más joven y más ágil, regularizo su funcionamiento antes que las más antiguas. En ella gane por concurso mi primera plaza universitaria (SÁNCHEZ ALBORNOZ, 2012: 189).

Sin embargo, a poco más de un año de haber comenzado a dar clases en la UNS y ante las propuestas de trabajo recibidas de otras universidades del interior, decidió trasladar sus actividades a la ciudad de Rosario. Al respecto de los motivos de dicha decisión el mismo Sánchez Albornoz nos dice que

\begin{abstract}
Por más que dispusiera de una designación firme en la Universidad Nacional del Sur, prefería enseñar lo mismo en la del Litoral. La ciudad de Rosario, sede la citada facultad santafesina, distaba menos y se hallaba mejor comunicada con Buenos Aires, donde residía mi familia. Por un tiempo, hube de compaginar con gran esfuerzo mis enseñanzas en Bahía Blanca y en Rosario hasta consolidar mi plaza en el segundo lugar. Solo entonces renuncié a la cátedra ganada en Bahía Blanca (SÁNCHEZ ALBORNOZ, 2012: 190).
\end{abstract}

Nicolás Sánchez Albornoz, continuó trabajando en Argentina en distintas cátedras de historia en las Universidades del Litoral y de La Plata, hasta que, en 1966, debido a las políticas de intervenciones, censuras y persecuciones en el ámbito educativo puestas en marcha por un nuevo gobierno militar en Argentina decidió regresar a España.

Por su parte, Manuel Lamana, después de dar clases de francés en la Alianza Francesa de Buenos Aires entre 1954 y1958 logró finalmente un cargo como Profesor de Letras en la cátedra -recientemente abierta- de Literatura Contemporánea en la UNS. Durante los dos años siguientes llevó a cabo una intensa actividad académica e 
intelectual en la ciudad de Bahía Blanca, que fue acompañada de frecuentes viajes a Tucumán donde también logró desempeñarse como profesor de literatura. Una vez iniciada la década del sesenta abandonó sus trabajos en Bahía Blanca para desempeñarse en otras ciudades del interior y en Buenos Aires, permaneciendo en el país hasta su muerte en 1996.

La mayoría de los profesores exiliados enseñaron durante cortos períodos de tiempo en distintas universidades, con una clara predominancia de aquellas situadas en el interior del país ante las dificultades para insertarse en el medio académico capitalino. Sin embargo, el horizonte de poder ejercer sus profesiones en Buenos Aires permaneció en muchos de ellos dada la relevancia cultural del mismo y las cuestiones afectivas puestas en juego. Estas últimas se generaban a partir de que las familias de los profesores exiliados permanecieron en Buenos Aires, mientras los mismos viajaban por los distintos centros educativos del interior, por lo que conseguir trabajo en la capital o cerca de ella se convertía en un objetivo de importancia.

A su vez, estos rápidos cambios de residencia y de trabajo de los profesores exiliados fue alentada por la política de atracción de las universidades del interior a través de contratos, que solían finalizar una vez que sus pares locales se encontraban en condiciones de acceder a los cargos. También contribuyó a este panorama la gran volatilidad de la política nacional con tendencia represiva creciente, que convirtió en poco tiempo a profesores reconocidos por su prestigio académico en educadores sospechados por su filiación política de izquierda y su condición de extranjero.

La irrupción del peronismo en la escena política nacional y local, abrió una etapa de división antagónica en la sociedad civil entre los heterogéneos campos del peronismo y el antiperonismo. Ambas identidades deben ser leídas en términos de configuraciones relacionales con lenguajes y cadenas de equivalencias propias que tuvieron su origen en el contexto de la Segunda Guerra Mundial. Para Grimson, el antiperonismo abreva en la combinación de tres perspectivas: el enfoque patronal, la concepción sarmientina de civilización y barbarie y la tradición antifascista (GRIMSON, 2019: 68). Los profesores exiliados republicanos integraron las redes antiperonistas desde su pertenencia política al amplio campo del antifascismo ${ }^{15}$. Dicha posición se sustentaba -a su entender- en la

\footnotetext{
${ }^{15}$ La adhesión a las redes antiperonistas no significó para la totalidad de los exiliados republicanos la entera desvinculación de las redes peronistas. La labor realizada desde sus arribos en institutos y cátedras de cultura hispánica fue clave para proveer a su subsistencia durante los gobiernos de Perón. Como ejemplo de lo dicho, Claudio Sánchez Albornoz realizó un importante trabajo desde sus cargos en el
} 
reticencia a defender la declaración de guerra al Eje por parte del gobierno anterior del cual Perón había sido Secretario de Trabajo y Previsión, Ministro de guerra y Vicepresidente; en el viaje de Perón a Italia durante el gobierno de Mussolini; en su condición de militar; en la presencia de nacionalistas y admiradores del franquismo en su gobierno ${ }^{16}$; en su anticomunismo y en las intervenciones políticas en el ámbito universitario que incluyeron entre otras medidas, el despido de docentes. Al igual que el peronismo, pero en un sentido diverso, la dictadura devenida de la proclamada Revolución Libertadora en 1955 también dividiría al campo intelectual, obligando a los distintos sujetos a posicionarse frente a la desperonización (FIORUCCI, 2011).

Los años transcurridos entre 1955 y 1966, constituyen para la historiografía canónica nacional una "Edad oro" de las universidades nacionales, en la cual se produjo el despliegue del proyecto reformista de universidad laica y moderna que reactualizó las concepciones de autonomía y cogobierno universitario y favoreció la creación de nuevas ofertas de formación y la expansión de dedicatorias docentes exclusivas. Este panorama, generó condiciones favorables -sin soslayar las múltiples tensiones existentes en las redes de exiliados hacia su interior como en sus fricciones de distinto grado con redes localistas- para la inserción académica y el desarrollo laboral e intelectual de los exiliados republicanos. Los distintos debates y procesos políticos a escala nacional producidos en esos años, tales como los efectos de la desperonización o el debate "libre o laica" acerca de la posibilidad de las universidades privadas de emitir títulos habilitantes, tuvieron su expresión particular en Bahía Blanca coincidente con un mayor peso relativo del campo político-intelectual católico y antiperonista en la ciudad. Durante este conflicto entraron en tensión las identidades laicas y antiperonistas de los profesores exiliados con otros componentes de las redes locales que integraron, con los cuales compartían la oposición al gobierno peronista pero no su conservadurismo católico. Estas tensiones, como veremos, fueron minando progresivamente la relación entre agentes locales y exiliados.

En cuanto a la concepción del período como una "edad de oro" universitaria podemos mencionar algunas cuestiones que relativizan dicha idealización para el caso de la UNS. Al respecto, constatamos efectivamente en un primer momento una etapa de crecimiento presupuestario que se extiende aproximadamente entre 1956 y 1962, años

Instituto de Historia de España y en la UBA que le permitieron difundir sus estudios historiográficos y culturales hispánicos durante esos años.

${ }^{16}$ Entre los cuales se destacan las figuras de José Figuerola y Miguel Miranda. 
en los que se produce el arribo de profesores extranjeros mediante contratos que fortalecieron diversas líneas de investigación principalmente relativas a disciplinas humanísticas. En cambio, en un segundo momento, encontramos una agudización de los problemas financieros, que llevó al congelamiento de salarios y precipitó un aumento del conflicto con los trabajadores universitarios docentes y no docentes quienes expusieron en el debate público al interior y al exterior de la academia su preocupación por la situación económica entre 1962 y 1966. Este contexto limitó la llegada de nuevos profesores del exterior en carácter de conferencistas o como personal contratado. Al mismo tiempo, el cambio del perfil de una universidad con impronta humanística a una técnica-industrial, afectó los espacios de inserción profesional de los exiliados republicanos especializados en su totalidad a distintas disciplinas sociales. Por último, la expulsión de educadores vinculados al peronismo durante el período y la imposibilidad de su reingreso también debe ser tenida en cuenta a la hora de evaluar el supuesto apogeo de la universidad laica y reformista.

Sobre el final del período, se produce una agudización de las tensiones entre los profesores locales y sus pares extranjeros entre los que se encontraban los exiliados. En este sentido, La Nueva Provincia, medio gráfico de importante impacto en la opinión pública bahiense, publicó una editorial en la cual planteó lo siguiente:

Queremos significar lo siguiente: la UNS es parte de Bahía Blanca. Es fruto de la lucha de los bahienses y los sureños en general, mantenida a lo largo de décadas, por contar con una Casa de Estudios Superiores. Los bahienses, aunque más no sea que por eso, sentimos hondo cariño por nuestra Universidad y estamos identificados con ella. Si se pudiera a su frente a un profesor, a un doctor o a un ingeniero, nativo o de vieja residencia en Bahía Blanca, que acreditara los suficientes méritos y conocimiento de 'nuestro' problema universitario, aunque su figura no se presente nimbada de lauros y prestigio, creemos que las cosas podrían andar mejor (LA NUEVA PROVINCIA, 06/04/1958).

Como efecto de este cambio de perspectiva y de las reuniones que se comenzaron a realizar entre los profesores locales, un mes más tarde se impuso una medida que obligó a todos los educadores universitarios a residir en Bahía Blanca como requisito para poder acceder no solo a un cargo político sino a una plaza en una cátedra. 
Sin embargo, existieron voces principalmente salidas del claustro estudiantil y su principal agrupación: la Federación Universitaria del Sur que defendieron públicamente a los profesores extranjeros, en contra del hecho de que sus pares locales, a su juicio sin experiencia ni formación, cubrieran las cátedras que quedaban libres (FERNÁNDEZ STACCO, 2009: 207-208).

En lo referido a la actuación de los profesores exiliados en las cátedras de la UNS, podemos destacar dos cuestiones. La primera de ellas es la innovación pedagógica que introducen en los programas que elaboran. Al respecto, vale mencionar el programa presentado por Alberto Vilanova para la cátedra Historia de España en 1960, en donde incorporó unidades no presentes en programas anteriores acerca de la historia de la Segunda República y de la Guerra civil la cual fue nombrada como “Guerra de Invasión”. La segunda, es la coexistencia de dos profesores en una misma materia -única registrada en el Departamento de Humanidades en el período analizadodentro de la cátedra Teoría y Metodología de la Historia a cargo de Vilanova Rodríguez y de Exequiel Ortega ${ }^{17}$ durante el período 1960-1965. En esta etapa, los mismos introdujeron progresivamente nuevas temáticas como "la historia y la revolución" abordadas desde bibliografía escrita por historiadores y filósofos republicanos como Ortega y Gasset y Zacarías García Villada ${ }^{18}$. Además, durante este período comenzaron a intervenir de manera más activa en la política universitaria, en especial Exequiel Ortega, debido a que Vilanova Rodríguez como el resto de los exiliados y profesores extranjeros tenían vedada -debido a cuestiones reglamentarias que solicitaban residencia en la ciudad o directamente negaban el derecho a ser elegidos a los extranjeros - la participación y voto en algunos de los órganos de gobierno universitario. En 1961 es propuesto Ortega como candidato a rector con el apoyo del Centro de Egresados y de la Federación Universitaria del Sur - ambas listas tanto la de graduados como la de estudiantes adherían al reformismo con un fuerte contenido político- quedando finalmente en segundo lugar (FERNÁNDEZ STACCO, 2009: 262).

En este contexto, la participación institucional de los exiliados se redujo a responder a las convocatorias realizadas por las autoridades universitarias de turno. De esta forma, encontramos que Nicolás Sánchez Albornoz participó, por pedido del Rector

${ }^{17}$ Exequiel Ortega (1915-2012) historiador nacido en Pehuajó, autodefinido como humanista y como un defensor de los valores democráticos, tras su paso por la UNS como Profesor de Teoría y Metodología de la Historia, accedió a distintas plazas en la UNLP, llegando a ser decano de la Facultad de Humanidades.

${ }^{18}$ Entre los textos propuestos desde la cátedra se encuentran Historia como sistema (1935) y La rebelión de las masas (1929) de Ortega y Gasset y Metodología y Crítica históricas (1921) de Villada. 
Fatone en 1957, en la comisión para la organización de los primeros estatutos y planes de estudios y que Hernández Ibáñez fue enviado como delegado a un viaje a la Patagonia y a Rio Cuarto con motivo de la puesta en marcha de la Semana Geográfica (LA NUEVA PROVINCIA, 04/02/1959).

Durante su permanencia en la UNS los exiliados republicanos publicaron dos trabajos en la revista Cuadernos del Sur del Departamento de Humanidades, ambos editados en el año 1960. Estos artículos son La novela de la postguerra escrito por Manuel Lamana y Oratoria política y oradores del ochocientos de Rafael Olivar Bertrand. En ellos, se conjugaron temáticas de análisis literario con cuestiones de fuerte contenido político, siempre presentes en su discurso académico. Esta fusión de contenidos que realizaron los exiliados en sus escritos se aprecia claramente en uno de los fragmentos de la producción de Lamana: "En un país como el mío, cuando un hombre va alcanzando la noción de la exacta responsabilidad y quiere mostrar su disconformidad con tantas cosas, si lo manifiesta no es raro que le encarcelen. No estoy haciendo política, quiero advertirlo. Hablo de una situación que incide directamente en la producción literaria" (LAMANA, 1960:5).

\section{La participación de los profesores exiliados en las redes culturales bahienses}

La filial del CLES de la ciudad de Bahía Blanca se fundó en 1941 bajo el impulso del abogado socialista Pablo Lejarraga. El órgano de publicación del Colegio era la revista trimestral Cursos y Conferencias donde se publicaban discursos y trabajos producidos en distintos filiales vinculados a lo académico, pero con un visible tinte político.

Entre sus objetivos iniciales expuestos en su Acta de Fundación del 20 de mayo de 1931 leemos los siguientes:

[El CLES] Constará de un conjunto de cátedras libres, materias incluidas o no en los planes de estudio universitario, donde se desarrollarán puntos especiales que no son profundizados en los cursos generales (...) de las Facultades. Ofrecerá sus cátedras a profesores universitarios de reconocida autoridad y a las personas que fuera de la universidad se hayan destacado por 
su labor personal [...] Ni Universidad profesional, ni tribuna de vulgarización [...] Germen modesto de un esfuerzo en favor de la cultura superior, espera la contribución material, intelectual y moral de todas las personas interesadas en que aquélla sea un elemento de acción directa en el progreso social de la Argentina.

Entre la mencionada propuesta del CLES cercana al krausismo ${ }^{19}$ español liberal ligada a la Institución Libre de Enseñanza (ILE) ${ }^{20}$ y el proyecto educativo implementado por la Segunda República Española, encontramos una serie de coincidencias entre las que destacamos la importancia dada a la enseñanza universitaria pero también a las cátedras abiertas por fuera de ella; la centralidad de la flexibilidad pedagógica para adaptarse a las nuevas necesidades del momento, deconstruyendo el antiguo modelo autoritario-memorístico para promover un nuevo enfoque críticoreflexivo y la consideración de la enseñanza como medio predilecto para el progreso social y la acción transformadora. Como afirma Salomó Marqués Sureda este "el model escolar republicá, és el que fora de la seva patria la gran majoría de mestres exiliats continuaren practicant als paísos que els varen acollir." (SUREDA, 2008: 59).

Coincidiendo con esta propuesta educativa y sus bases ideológicas, los republicanos llegados a Bahía Blanca participaron de las publicaciones Cursos y Conferencias durante el período 1956-1960, año de desaparición de la revista. En esta etapa, observamos una intensa actividad de los exiliados junto a profesores e intelectuales argentinos -insertos en la UNS y en otros espacios de la cultura bahiense- y a otros exiliados que se encontraban residiendo en otras regiones, en la sección denominada Vida del Colegio, donde se relataron las principales actividades llevadas a cabo por cada filial del Colegio.

Entre estas actividades podemos mencionar: en primer lugar, el arribo de Luis Jiménez de Asua $^{21}$ para dictar una conferencia en Bahía Blanca respondiendo a la

\footnotetext{
${ }^{19}$ El krausismo es una doctrina que defiende la tolerancia académica y la libertad de cátedra frente al dogmatismo. Debe su nombre al pensador postkantiano alemán Karl Krause (1781-1832). Esta filosofía tuvo gran difusión en España, donde alcanzó su máximo desarrollo práctico gracias a la obra de su gran divulgador, Julián Sanz del Río, y a la Institución Libre de Enseñanza dirigida por Francisco Giner de los Ríos.

${ }^{20}$ La Institución Libre de Enseñanza fue un proyecto pedagógico inspirado en la filosofía krausista que se desarrolló en España entre 1876 y 1936.

${ }^{21}$ Luis Jiménez de Asúa (1889 - 1970) fue un jurista y político español que se desempeñó como vicepresidente del Congreso de los Diputados y representante de ese país ante la Sociedad de Naciones.
} 
invitación de Pablo Lejarraga (Revista Cursos y Conferencias, 12/1957: 65). En segundo lugar, la colaboración en conjunto durante la puesta en marcha del programa de actividades del CLES para el año 1957, entre el propio Lejarraga, los profesores Hernández Ibáñez, Monasterio y Vicente Fatone que en ese momento se desempeñaba como rector de la UNS y como miembro del Consejo Directivo del Colegio. En tercer lugar, la participación de Lejarraga y Fatone en el Homenaje a Martínez Estrada -en el que él mismo es conferencista- por el "25 aniversario de Radiografía de la Pampa" propuesto por la UNS y por el CLES (REVISTA CURSOS Y CONFERENCIAS, 04/1959: 103). En cuarto lugar, la participación de Manuel Lamana en un ciclo de Conferencias en la que disertó acerca de Ortega Gasset y la juventud española -que fue publicada posteriormente en la revista Cursos y Conferencias- junto a otros conferencistas argentinos como Andrés Ringuelet profesor en la UNLP de tendencia anarco-libertario. En quinto lugar, la participación de Vilanova Rodríguez como disertante en una conferencia titulada La revolución de Mayo y España durante un homenaje a la Revolución de Mayo en la que interviene con Pablo Lejarraga. En sexto lugar, la exposición de Hernández Ibáñez acerca del Determinismo geográfico y las pasiones humanas y por último la intervención de Monasterio mediante una ponencia titulada Amor insoslayable. Dinámica de algunos afectos fundamentales en un ciclo de conferencias llevado a cabo por el CLES entre septiembre y noviembre de 1957.

Además de la participación de los exiliados en las redes del CLES mencionadas, destacamos la publicación de un artículo escrito por Manuel Lamana en 1959, titulado José Ortega y Gasset y la juventud actual de España. En este artículo abordó los silencios de la España de fines de la década de 1950, reflexionando sobre la actualidad española y los temores que generaban entre los exiliados, un posible retorno en el que colisionaran la "España real" con la "España imaginada". Al respecto resulta reveladora la siguiente cita:

No puedo evitar el decir que es triste cómo actualmente la lección y la enseñanza de aquellos años guerra son ya como fría historia leída, para los jóvenes universitarios de hoy, los hijos de los que lucharon por una España mejor. Es decir, de los que vencieron y de los que perdieron, todos ellos.

Durante la dictadura franquista se exilió en Argentina donde vivió hasta su muerte, trabajando en distintas universidades nacionales y ejerciendo funciones en los órganos de gobierno de la República en el exilio. 
Porque todos ellos viven hoy entremezclados en los pasillos y en las aulas de la Ciudad Universitaria de Madrid (LAMANA, 1959: 39-40).

A su vez, encontramos en las revistas Cursos y Conferencias publicaciones como la siguiente denuncia firmada por docentes de la Facultad de Filosofía y Letras de la UBA titulada Las detenciones en Barcelona, en la cual se repudió "El hecho consumado por el régimen franquista, que ordenó detener a varios catedráticos barceloneses y algunos estudiantes por haber censurado el totalitarismo imperante en España" ${ }^{22}$. Tras lo dicho, entendemos que la línea política tomada desde el CLES resultó de gran relevancia a la hora de que los exiliados decidieran participar en sus publicaciones y actividades.

En cuanto a la Asociación Bernardino Rivadavia, constatamos la existencia de una estrecha red de colaboración entre aquellos agentes que intervinieron en ésta y en el CLES, quienes a su vez participaban en clubes sociale, colegios profesionales, corporaciones económicas, partidos políticos tradicionales y, luego de su creación, en la UNS.

Siguiendo lo dicho por Juliana López Pascual, ésta

Inserción institucional múltiple y heterogénea se presenta, $[\ldots]$ como una valiosa y productiva estrategia de religación social que permitía a los actores articular lazos de diferentes cualidades y construir capitales sociales complejos. En ellos se yuxtaponían las pautas modernas de asignación del prestigio - definidas en torno a la dimensión individual - con algunos elementos que remitían a estructuras propias de sociedades de mayor antigüedad, como las ligazones familiares y los parentescos políticos (LÓPEZ PASCUAL, 2014: 319).

Es decir, que quienes participaron del mundo asociativo del CLES en Bahía Blanca se encontraron vinculados -o formando parte directamente en el- con el grupo de personas que lideraron otros espacios de sociabilidad y partidos políticos tradicionales no peronistas ${ }^{23}$. Estas elites locales coincidieron en sus preocupaciones en torno a la cultura entendida bajo los lemas modernos del progreso, la ciencia y la razón. De esta

\footnotetext{
${ }^{22}$ Revista Cursos y Conferencias $\mathrm{N}^{\circ} 283$ (12/1958: 303).

${ }^{23}$ Tal es el caso del abogado Pablo Lejarraga, importante dirigente del Partido Socialista local.
} 
forma "la estrecha relación sostenida con la Asociación Bernardino Rivadavia se entendió, en este contexto, como el alineamiento con las formas de la cultura laica, liberal y popular" (LÓPEZ PASCUAL, 2014: 287).

Esta comunión de intereses llevó a que una vez que la sede local del CLES fuese expropiada y cedida a la Confederación General del Trabajo por parte del Gobierno provincial en 1952, el Colegio trasladará todos sus actos públicos a la sala de la ABR, que se había convertido en un espacio abierto a los intelectuales opositores al peronismo $^{24}$.

En este período de convergencia entre los intereses y posicionamientos políticos de las asociaciones mencionadas, los dirigentes locales intentaron enriquecer y acrecentar el prestigio de los centros culturales locales mediante la participación de intelectuales y profesores extranjeros. Entre ellos, los exiliados republicanos constituyeron una elite debido tanto a su prestigio intelectual como a la cercanía entre las bases ideológicas de ellos y los centros receptores. De esta forma, se generó un beneficio mutuo entre los centros culturales que acumularon capital simbólico y prestigio y los exiliados que consiguieron acrecentar su capital relacional -clave para la inserción laboral- y un medio público en el cual poder transmitir sus reflexiones y denuncias sobre la actualidad española en la comunidad de acogida.

Como ejemplo de estos vínculos, Lejarraga buscó contactar mediante la intermediación de Carlos Ruiz Daudet -fuertemente vinculado a la sociabilidad cultural de izquierda- al dramaturgo ibérico exiliado en Argentina, Jacinto Grau y mediante José Luis Romero y Silvio Frondizi a Claudio Sánchez Albornoz, siempre con la intención de que viajen a la ciudad para colaborar con la entidad. Es decir que "los pensadores europeos exiliados en Argentina no sólo encontraron espacios de inserción laboral en las redes de solidaridad antifascista, sino que la conexión con ellos era buscada desde las instituciones provincianas por la valoración positiva de su prestigio intelectual y su adscripción ideológica" (LÓPEZ PASCUAL, 2014: 76).

Entre los años 1956 y 1966 en la sede de la ABR se realizaron numerosas conferencias, exposiciones y conciertos en las que participaron las asociaciones españolas y regionalistas, fundamentalmente la Unión Vasca, y algunos de los profesores exiliados, como en el caso de la Conferencia acerca de la Geografía y la

\footnotetext{
${ }^{24}$ La inscripción de la ABR al campo antiperonista se había exacerbado luego del intento del gobierno peronista de anexar sus espacios físicos al Instituto Tecnológico del Sur, lo cual fue resistido por la mayoría de los asociados y su cúpula dirigente.
} 
pasión humana que brindó Hernández Ibáñez. Estas intervenciones -alrededor de cuarenta para el período estudiado- se inscribieron en el objetivo propuesto por las asociaciones étnicas españolas alineadas a la república, de erigirse como trincheras en la defensa de la cultura republicana española y regionalista, propósito en el cual los exiliados jugaron un papel fundamental. Dentro de este objetivo, mantener en vigencia los idiomas regionales que se hallaban prohibidos en la Península, se convirtió en un aspecto central.

Asimismo, consideramos que la participación de los exiliados republicanos en estas asociaciones se vio alentada por su convergencia en el amplio campo del antiperonismo. Tal como dijimos, el conflicto español significó la polarización de la intelectualidad local cuya división en dos frentes se volvió evidente. "El "mundo de los letrados" locales se separó así entre "fascistas y democráticos”, según apoyaran a Franco o a los Republicanos españoles. "La inteligencia liberal junto con la izquierda (más o menos cercana al liberalismo) expresó sus preferencias por la República, mientras que los nacionalistas se inclinaron en su conjunto por Franco" (FIORUCCI, 2001: 9).

El golpe militar de 1966 tuvo hondas repercusiones en el mundo cultural bahiense debido entre otras medidas a la intervención de la UNS (ORBE, 2007), que condujo a la sanción de un nuevo estatuto en conveniencia con el modelo restrictivo y represivo de la dictadura de Onganía. Esta intervención junto al cambio de rumbo escogido por la comisión directiva de la $\mathrm{ABR}^{25}$, provocaron una reducción de los espacios públicos de participación e inserción laboral de los profesores exiliados, quienes optaron por reinstalarse en otras ciudades del país, abandonar el mismo retornando a España aun en periodo franquista o asumir la autocensura como forma de permanecer en sus lugares de trabajo.

\footnotetext{
${ }^{25}$ El Consejo Directivo de la ABR emitió una demanda formal para que se le informara con anticipación el contenido de actividades futuras prohibiendo las manifestaciones "sobre propaganda política". Esto derivó en la renuncia Berta Gaztañaga de Lejarraga como vocal de la ABR y el rompimiento de los lazos con otras instituciones culturales y étnicas en las que participaban los exiliados "La Biblioteca Rivadavia es una entidad cuyos fines son de extensión cultural. Su tribuna de conferencias es y seguirá siendo libre [...] [lo] que se reclama no significa en ningún modo un reparo a la personalidad de los disertantes sino una comprensible prevención frente al eventual desborde de los temas. [...] El Consejo Directivo tiene conciencia de que su facultad para decidir en este caso puede ser vista como sumamente delicada en tanto se quiera ver en ella un indebido propósito de limitación a la libertad de expresión, pero de todos modos se trata de una facultad irrenunciable. También así es cierto que en nombre de la libertad podrían llegarse a confundir los límites del derecho" (Actas del Consejo Directivo de la ABR - Archivo de la Asociación Bernardino Rivadavia).
} 


\title{
El exilio dentro del exilio
}

Cuatro años duró la travesía que llevó a Ricardo Arenales de La Habana, a Nueva York, Guatemala y El Salvador, y de regreso a México. En una carta que había escrito en 1916 desde La Ceiba - Guatemala a Alfonso Mora Naranjo, amigo suyo de la infancia, le decía:

\begin{abstract}
Allá [en Colombia] tienen muchos detalles de la ruina mía, debida a la revolución de México: perdí todo lo que había hecho en el orden material, y después he sufrido. Fuera de México, todo el mundo es miserable. México era el paraíso, Jaauja. Yo vi correr arroyos de leche y miel; yo vi montones de oro y subí a ellos. ¡Ah, mi México adorable y adorado!. ${ }^{26}$
\end{abstract}

La nostalgia lo llevó de regresó a México en 1918, esta vez, curiosa y contradictoriamente, al servicio del régimen constitucionalista, que lo había exiliado, como redactor del periódico oficialista El Pueblo. ${ }^{27}$ Este desde su fundación, en 1914, se habían convertido en uno de los bastiones del carrancismo, y junto con todo el aparato propagandístico del Estado, estaba enfocado en mejorar la imagen de la Revolución y en propagar sus ideales (MÉNDEZ LARA, 2016; FIGUEROA DAZA, 2010).

La campaña de propaganda del constitucionalismo había iniciado casi a la par con el levantamiento de Carranza contra el gobierno de Victoriano Huerta. Para su ejecución, tanto al interior de México como en Estados Unidos y Latinoamérica, habían sido llamados no solo los intelectuales mexicanos, sino todos aquellos latinoamericanos que sintieran alguna simpatía por el proceso revolucionario y se comprometieran, a través de sus escritos o giras continentales, a contrarrestar la campaña norteamericana de desprestigio a la Revolución

Este espíritu se vio reflejado en los escritos que a partir de 1918 publicó Ricardo Arenales en la prensa mexicana, marcando una clara diferencia con el polemista que fue

\footnotetext{
${ }^{26}$ Carta de Ricardo Arenales a Alfonso Mora Naranjo", La Ceiba, 6 de junio de 1916, en: (BARBA JACOB, 1992: 51).

${ }^{27}$ El Pueblo, periódico carrancista tuvo varios directores desde su fundación en 1914 hasta el cierre definitivo de sus oficinas en 1919. Ambos periódicos, por su duración, se convirtieron en los representantes del carrancismo triunfante (MÉNDEZ LARA, 2016; FIGUEROA DAZA, 2010).
} 
en Churubusco. Sus artículos de El Pueblo eran prudentes, reflejaban cierta expectativa frente a los avances de la revolución, y defendía a Carranza, haciendo eco de las exigencias que el gobierno hacía a la prensa subvencionada.

Con el cierre de El Pueblo en 1919, el énfasis de sus escritos no volvió automáticamente a ser la política, como lo había sido antes de su exilio. Por el contrario, dejaban ver su interés por rehuir del tipo de temas que le habían causado la expulsión. En ese sentido, desde las páginas de El Heraldo de México comenzó a publicar una serie de artículos amarillistas que hablaban de brujos y caníbales, de asesinatos y secuestros en la ciudad de México, de las reuniones que sostenía en el Palacio de la Nunciatura, entre otras cuestiones más bien superfluas. También contribuyó con un par de artículos a la campaña antidrogas abanderada por dicho periódico. Escribió en contra de la mariguana, la cocaína y el opio, de los que se sabe era asiduo consumidor. ${ }^{28}$

Arenales también se vio impregnado por los discursos latinoamericanistas del momento. En el prólogo de su libro Rosas Negras, publicado en 1920, defendía la idea, común entre los intelectuales de la época, de que a México le correspondía la dirección del movimiento hispanoamericano.

México está al norte, -decía su escrito-, en los confines del mundo de Bolívar; tiene sus raíces que se prolongan hasta más allá del advenimiento de Colón; posee una fisionomía confusa, pero propia y auténtica; se desborda con el paso huracanado de sus guerrilleros, que no es sino indicio de fuerzas sin cauce; ha sepultado dos imperios; y lo que es más importante, acepta la suprema delegación que le hacen con tácita voz los pueblos fraternos (BARBA JACOB, 1984: 74-75).

Destaca el poeta en este pasaje el papel que México se había arrogado como hermano mayor de los pueblos del sur, debido, principalmente, a la posición geográfica que lo enfrentaba al coloso del norte. Como frontera de los confines del mundo de

\footnotetext{
${ }^{28}$ Ricardo Arenales, "La dama de cabellos ardientes se bebe la vida de sus amantes", El Heraldo de México, México D.F., 26 de julio de 1919, en: (GARCÍA AGUILAR, 2010: 236-240); Ricardo Arenales, "En pleno reinado de 'El ídolo blanco"”, El Heraldo de México, México D.F., 1 de agosto de 1919, en: (GARCÍA AGUILAR, 2010: 241-246); Ricardo Arenales, "El opio produce primero sueños bellos y visiones plácidas, después pesadillas, y al final la muerte", El Heraldo de México, México D.F., 3 de agosto de 1919, en: (GARCÍA AGUILAR, 2010: 247-253).
} 
Bolívar, México abanderaba, según él, la defensa de la soberanía de los pueblos fraternos del sur.

Con el asesinato de Carranza en Tlaxcalantongo, y la llegada a la presidencia del general Álvaro Obregón, el poeta colombiano volvió a hablar de política mexicana. En El Demócrata, ${ }^{29}$ por ejemplo, periódico en el que entró a colaborar en 1921, defendió posiciones totalmente contrarias a aquellas que le habían valido la expulsión en 1914. En esta oportunidad, solo por poner un ejemplo, contrario a las críticas que había levantado en contra del Ejercito Libertador del Sur desde Churubusco en 1914, propagó una imagen positiva, y hasta heroica del general Emiliano Zapata. ${ }^{30}$ Esta posición le sirvió, de paso, para criticar a Venustiano Carranza, ahora con el respaldado que el clima anticarrancista de los primeros años de la década de 1920 les brindaba a los opositores del expresidente asesinado. ${ }^{31}$

También se inscribió, a su manera, en el debate de la época: las disputas por el significado del concepto de revolución. Con el triunfo de la Revolución de Octubre, y el entusiasmo que esta despertó en algunos sectores sociales y, en contraposición, el miedo que provocó en otros, la Revolución mexicana comenzó a ser interpelada por esa otra revolución triunfante. Desde Estados Unidos se impulsó una campaña que pretendía igualar un proceso con el otro, con el objetivo de denunciar las supuestas arbitrariedades que los revolucionarios mexicanos estaban cometiendo, según ellos, influenciados por el bolchevismo. Mucha tinta corrió sobre si la opción para las revoluciones latinoamericanas debía ser el nacionalismo, del tipo mexicano, o el internacionalismo proletario; o si las trasformaciones sociales debían hacerse de manera gradual, a través de reformas sociales, o de manera violenta y en busca de cambios radicales.

El caso fue que el poeta colombiano aprovechó la oportunidad que le daba el ambiente antibolchevique para afilar su pluma en contra del presidente de la CROM, Luis N. Morones, al que acusaba de ser el "primer líder del bolchevismo mexicano". 32 La estrategia discursiva que utilizó para desprestigiar a Morones, y con ello a los

\footnotetext{
${ }^{29}$ El Demócrata, dirigido por Rafael Martínez, con un marcado carácter propagandístico fue concebido como un periódico itinerante, en tanto se trasladó con el Primer Jefe por toda la República hasta que el gobierno logró asentarse definitivamente en la ciudad de México en 1915. Se publicó hasta abril de 1926, fecha en que se clausuró definitivamente.

${ }^{30}$ Ricardo Arenales, "El sacrificio de Emiliano Zapata no ha sido estéril", El Demócrata, México D.F., 10 de abril de 1921 (GARCÍA AGUILAR, 2010: 120-122).

${ }^{31}$ Ricardo Arenales, "La Silueta de Don Pablo", El Demócrata, México D.F., 19 de abril de 1921 (GARCÍA AGUILAR, 2010: 123-126).

${ }^{32}$ Ricardo Arenales, "Ecce Homo", El Demócrata, México D.F., 17 de mayo de 1921, en: (GARCÍA AGUILAR, 2010: 147-149).
} 
bolcheviques, fue la de disminuir su presencia e importancia en el medio mexicano. Le acusó de ser un "parlanchín de taberna" "una realidad pequeña, opaca, circunscrita y sin trascendencia posible, en el orden de las ideas". ${ }^{33}$ Estrategia muy común a la hora de criticar las organizaciones obreras inspiradas en la revolución de octubre, aunque esto no significara que Morones comulgara con los bolcheviques. El peligro del discurso de Morones, según Arenales, era que contribuía a mantener "la cuarentena diplomática de los Estados Unidos", y con ello la huida de capitales norteamericanos, situación que hacía "más lenta y difícil la marcha del progreso y el advenimiento de la paz al santuario de las conciencias". 34

En un primer momento la crítica a Morones le permitió al poeta colombiano inscribirse, de una manera u otra, en los esfuerzos de la diplomacia mexicana por obtener el reconocimiento de Estados Unidos (PALACIOS \& COVARRUBIAS, 2011: 205). Pronto, esta crítica lo llevó a dirigir su pluma contra el Secretario de Gobernación, Plutarco Elías Calles. Desde las páginas del recién fundado periódico capitalino Cronos, propiedad de Ignacio Muñoz, denunció la ambición del general sonorense y sobre todo su responsabilidad en el agitado ambiente social que se vivía en el México de inicios de 116 la década de $1920 .^{35}$

Con el cinismo que lo caracterizaba escribió un artículo criticando a la prensa subvencionada, desde Porfirio Díaz hasta Carranza, haciendo caso omiso, al parecer, que su participación en El Pueblo en 1918, le había dado la oportunidad, no solo de regresar al país luego de cuatro años de exilio, sino de resolver su vida en términos económicos. En dicho artículo afirmaba que Cronos, "primer diario de la mañana, provisto de elementos modernos para su desarrollo, que se opone al gobierno sin tibiezas ni medias tintas", había surgido como respuesta a ese periodismo que, si bien no tenía que lamentar atropellos, estaba virtualmente amordazado, y aparecía ante la opinión pública como un periodismo corrupto y descompuesto. Afirmaba también que como diario independiente no estaba unido a la Secretaría de Gobernación "por el ombligo de los gastos secretos". ${ }^{36}$ En este sentido Cronos, al defender, según el poeta, un programa radicalmente opuesto al de la Revolución, como diario independiente, se

\footnotetext{
${ }^{33}$ Ricardo Arenales, "El Bolcheviquismo y la Revolución Mexicana", El Demócrata, México D.F., 25 de mayo de 1921, en: (GARCÍA AGUILAR, 2010: 150-152).

${ }^{34}$ Ibíd.

${ }^{35}$ Ricardo Arenales, "Una Interrogación Angustiosa", Cronos, México D.F., 16 de junio de 1922, en: (GARCÍA AGUILAR, 2010: 174-176).

${ }^{36}$ Ricardo Arenales, "Sin Coyunda", Cronos, México D.F., 26 de junio de 1922, en: (GARCÍA AGUILAR, 2010: 183-185).
} 
convertiría en la prueba definitiva de que el régimen revolucionario sí garantizaba la libertad de pensamiento, como lo aseguraba con insistencia el Secretario de Gobernación. ${ }^{37}$

Fue de esta manera, como una vez más, como lo hiciera desde Churubusco, convirtió en blanco de sus ataques al régimen de la revolución. Sus más mordaces críticas las dirigió en contra de Calles, a quien acusó de utilizar todo su poder como Secretario de Gobernación para enfilar sus pasos hacía la presidencia de la república. ${ }^{38}$ Aseguraba que el general sonorense suscitaba la agitación de los gremios obreros para su beneficio.

Agitación estéril, que asume formas de violencia y que, haciendo de una clase social el único objeto de la solicitud del gobierno, le inmola como víctimas propiciatorias a las demás clases - que forman la mayoría de los habitantes de la república -, sin que, a la postre, los mismos obreros hayan obtenido la realización de uno solo de sus ideales legítimos. De tal suerte, todo el comunismo de México se trueca en una simple máquina de elecciones al servicio del general Calles. ${ }^{39}$

Aseguraba que Calles estaba usando a las organizaciones obreras para su beneficio, igual que Carranza había movido a los obreros contra Villa y la Convención, ${ }^{40}$ y así como este, los traicionaría en algún momento. Para Arenales el movimiento obrero mexicano no era más que "una marejada artificial provocada con fines políticos, en provecho de hombres egoístas y ambiciosos". ${ }^{41}$ Lo que en $E l$ Demócrata leía como una válvula de escape, los artículos 23 y 123 de la constitución, ${ }^{42}$ ahora los veía como un exceso contra el capital: "la comedia con que se engaña a los

\footnotetext{
${ }^{37}$ Ricardo Arenales, “¿Sí o no?, Cronos, México D.F., 30 de junio de 1922, en: (GARCÍA AGUILAR, 2010: 188-189).

${ }^{38}$ Ricardo Arenales, “Una Interrogación Angustiosa”, Cronos, México D.F., 16 de junio de 1922, en: (GARCÍA AGUILAR, 2010: 174-176).

39 Ricardo Arenales, "Una Interrogación Angustiosa”, Cronos, México D.F., 16 de junio de 1922, en: (GARCÍA AGUILAR, 2010: 174-176).

${ }^{40}$ Ricardo Arenales, “Cronos y los obreros”, Cronos, México D.F., 18 de junio de 1922, en: (GARCÍA AGUILAR, 2010: 177-178).

${ }^{41}$ Ricardo Arenales, “Cronos y los obreros”, Cronos, México D.F., 18 de junio de 1922, en: (GARCÍA AGUILAR, 2010: 177-178).

${ }^{42}$ Ricardo Arenales, "El bolchevismo y la Revolución Mexicana”, El Demócrata, México D.F., 25 de mayo de 1921, en: (GARCÍA AGUILAR, 2010: 150-152).
} 
mismos obreros y que no es, en resumidas cuentas, sino la preparación de un futuro despotismo". 43

Como puede verse, lo que comenzó como una crítica a Morones, enmarcada en la campaña gubernamental adelantada para contrarrestar la propaganda norteamericana en contra de la revolución mexicana, presuntamente asociada con la revolución rusa, terminó en una dura crítica a la alianza que el gobierno mexicano había establecido con sectores obreros y agraristas para garantizar su permanencia en el poder. Crítica que volvió a poner al poeta colombiano en la mira de los gobernantes revolucionarios.

A raíz de esto, por orden del presidente de la república, Ricardo Arenales fue detenido y enviado a la frontera con Guatemala: "Estaba en un país para él desconocido, sin un centavo en los bolsillos y con el traje que llevaba puesto como todo equipaje". ${ }^{44}$ Una vez más el colombiano había tomado una posición política que lo ubicaba del lado más conservador de la contienda, y que terminó causándole poderosos enemigos.

El 26 de julio de 1922 el cónsul de Colombia en México, Julio Corredor Latorre, informó al Ministro de Relaciones Exteriores en Bogotá que el gobierno mexicano había aplicado el artículo 33 constitucional a Ricardo Arenales por haberse inmiscuido en los asuntos políticos e internos mexicanos. ${ }^{45}$

El artículo 33 se convirtió en la herramienta más expedita con que contó el Estado mexicano para librarse de aquellos extranjeros que consideraba perniciosos y dañinos. Sin embargo, esto no significó que haya sido usado con asiduidad. La voluntad política de firmar una orden de expulsión requería de una coyuntura específica en la que se contemplara "la naturaleza y conflictividad del delito que se atribuía al extranjero, su nacionalidad, la capacidad del potencial expulsado para movilizar influencias que pudieran frenar o revocar la decisión presidencial y, fundamentalmente, la voluntad de

\footnotetext{
${ }^{43}$ Ricardo Arenales, “Cronos y los obreros”, Cronos, México D.F., 18 de junio de 1922, en: (GARCÍA AGUILAR, 2010: 177-178).

${ }^{44}$ Carta de Porfirio Barba Jacob a Enrique González Martínez, 15 de diciembre de 1925, La Habana, (BARBA JACOB, 1992:105)

${ }^{45}$ Según el artículo 33 de la Constitución de 1917, a los extranjeros no solo les está prohibido inmiscuirse en la política mexicana, sino que el titular del Ejecutivo está facultado para expulsarlos sin necesidad de juicio previo. Según Pablo Yankelevich (2011: 88) este artículo coloca al extranjero en una situación de manifiesta indefensión, "toda vez que por su aplicación se suspenden garantías individuales que la misma Constitución otorga a quienes residen en el territorio nacional".
} 
hacer evidente el control, las limitaciones y prohibiciones a las que estaba sometido todo extranjero por parte del poder público". 46

Así que, en el marco de la agitada vida política mexicana de los primeros años de la década de 1920 se dio una de aquellas coyunturas. Desde la Secretaría de Gobernación se había externado el propósito de terminar lo que denominaban una "campaña de injurias y falsedades" 47 desarrollada al interior de la República con apoyo de la prensa extranjera. Para los efectos de esa campaña en el extranjero ya se había afilado la batería propagandística del Estado a través de las representaciones diplomáticas mexicanas. Hacía el interior quedaba, no solo la misma propaganda, sino de manera complementaria la expulsión, o amenaza, de aquellos extranjeros inmiscuidos en la tarea de difamar al gobierno, como fue el caso de Arenales.

En el informe del cónsul colombiano relataba que no era la primera vez que esto le sucedía al poeta colombiano, recordando los sucesos de 1914 cuando había sido expulsado por la misma razón. Denunciaba de igual manera el oportunismo con el que Arenales había actuado durante sus años en México, ya que, así como había atacado a la revolución, también se había servido de ella, para luego volverla a atacar. Por estas razones el cónsul justificaba su posición de no interceder por Arenales ante el gobierno mexicano, en tanto obedecía "a la creencia de que no debe protegerse a los colombianos que se inmiscuyan en política interna del país extranjero en que residen, máxime si han recibido, como el señor Arenales, franca hospitalidad y no pocas prebendas de parte de los mexicanos". 48

Efectivamente Arenales no había dudado a la hora de poner su pluma al servicio del mejor postor. En realidad, el oficio de periodista era secundario para él, lo que realmente le llenaba como escritor era su poesía, lo que no significa que haya transitado libremente por un amplio margen de posiciones políticas. En realidad, siempre se movió en los contornos del conservadurismo, en tanto tuvo como líneas inamovibles de su pensamiento, por una parte, su devoción por Porfirio Díaz, que plasmó en más de una ocasión en sus escritos y que le llevó a defender a Huerta en 1914; y, por otra, su creciente desconfianza por al bolchevismo, que le llevó, como vimos, a transitar de una

\footnotetext{
${ }^{46}$ El trabajo de Pablo Yankelevich, ¿Deseables o inconvenientes?: las fronteras de la extranjería en el México posrevolucionario (2011), hace un análisis detallado de la política migratoria mexicana y en particular de la aplicación del artículo 33 constitucional en la primera mitad del siglo XX.

47 “serán expulsados los extranjeros perniciosos”, El Maestro, México, 1 de mayo de 1921, n², p. 103.

${ }^{48}$ Carta del cónsul encargado de Colombia en México, Julio Corredor Latorre, al Ministro de Relaciones Exteriores, 26 de julio de 1922, México D.F., AGN, Colombia, Ministerio de Relaciones Exteriores. Diplomática y consular, Consulado de Colombia en México, c. 646, carp. 108, f. 104.
} 
presencia más o menos neutral y apolítica en los primero años de su regreso a México en 1918, a ocupar una vez más su pluma en la critica a los revolucionarios, esta vez en contra de Plutarco Elías Calles y Luis N. Morones, figuras descollantes y protagonistas del México revolucionario de la década de 1920.

Este último exilio llevó al poeta a "asesinar a Ricardo Arenales", haciendo uso de sus propias palabras, y a darle origen a su último más conocido seudónimo Porfirio Barba Jacob. Existen muchas versiones sobre este cambio de nombre, alimentadas muchas de ellas por la imaginación del poeta, y recogidas en varios lugares por sus coetáneos.

\section{Consideraciones finales}

Si bien los profesores exiliados republicanos se integraron de formas diversas a las redes académicas y culturales existentes en la ciudad de Bahía Blanca, a partir de la reconstrucción de sus trayectorias podemos establecer las siguientes características comunes:

1. El arribo a la ciudad de Bahía Blanca se produjo a partir de la creación de la UNS en 1956. Las vacantes generadas para cubrir cátedras en la misma, las políticas de atracción generadas mediante la formalización de contratos y la imposibilidad para insertarse laboralmente en los medios académicos porteños contribuyeron al traslado de los exiliados desde otras regiones argentinas a Bahía Blanca.

2. Los profesores exiliados integraron redes identificadas con el heterogéneo mundo del antiperonismo, al cual adhirieron desde su tradición republicana y antifascista, asemejando en sus observaciones al peronismo con el franquismo.

3. Dentro del grupo de profesores exiliados hubo quienes pusieron su capital simbólico y cultural en debate en el espacio público local, tomando un rol de intelectuales. Tales fueron los casos de Nicolás Sánchez Albornoz y Manuel Lamana.

4. Los exiliados republicanos constituyeron una elite en las instituciones culturales en las que participaron -como el CLES y la ABR-generándose un beneficio mutuo en el que los centros culturales fortalecieron su prestigio y los exiliados consiguieron acrecentar su capital relacional y obtener un medio público en el cual poder transmitir sus reflexiones y denuncias. 
5. Para el período visto sobre la historia de la UNS debe relativizarse la concepción ampliamente difundida de la etapa como una "Edad de oro". Al respecto, podemos distinguir efectivamente un primer momento de crecimiento presupuestario que se extiende aproximadamente entre 1956 y 1962, en el que se produce el arribo de profesores exiliados, y una segunda etapa, entre 1962 y 1966 en la que encontramos una agudización de los problemas financieros que limitó la llegada de nuevos educadores del exterior. También notamos un cambio de perfil de una universidad con impronta humanística a una técnica-industrial, la agudización de las tensiones entre los profesores locales y sus pares extranjeros en competencia por recursos cada vez más escasos y la expulsión e imposibilidad de reingreso de docentes vinculados al peronismo.

6. Durante su permanencia en la UNS y en las asociaciones culturales, los profesores exiliados realizaron un importante aporte en la renovación de las líneas investigativas y de enseñanza, acorde con las propuestas de educación laica, científica, solidaria y centrada en el alumno de la Segunda República. En este sentido, actualizaron programas en las cátedras, intervinieron en la diagramación de proyectos interdisciplinares y de creación de carreras y contribuyeron a aplicar nuevos recursos educativos -como los cursos de verano- en los cuales se apuntó a desterrar el llamado memorismo generado por los exámenes de preguntas y respuestas, propiciando una formación crítica. Asimismo, en sus publicaciones denunciaron las políticas represivas implementadas por el franquismo y reflexionaron sobre la realidad española y las posibilidades de retorno.

7. Sobre el final del período, el golpe militar de 1966 tuvo hondas repercusiones en el mundo cultural y universitario bahiense, reduciendo los espacios públicos de participación e inserción laboral de los profesores exiliados, quienes optaron por reinstalarse en otras ciudades del país, retornar a España o en la menor cantidad de los casos permanecer en sus lugares de trabajo sin intervenir en el espacio público.

Por último, a partir del aporte del uso de la escala local en la elucidación de dinámicas exiliares analizadas a escala estatal y transnacional, podemos afirmar que si bien, dentro de la historia de los exilios intelectuales y universitarios, generalmente, se ha rotulado al exilio de los republicanos españoles como un exilio cultural, no debemos perder de vista la dimensión política que atravesó completamente sus formas de inserción, accionar y manifestaciones públicas. 


\section{Fuentes}

Archivo de la Asociación Bernardino Rivadavia (Bahía Blanca, período consultado 1956-1966).

Archivo de la Federación Regional de Sociedades Españolas (Bahía Blanca, período consultado 1939-1975).

Archivo de la Fundación Ezequiel Martínez Estrada (Bahía Blanca, período consultado 1956-1966).

Archivo de la Unión Vasca Laurak-Bat (Bahía Blanca, período consultado 1939-1975).

Archivo de la Universidad Nacional del Sur (Bahía Blanca, período consultado 19561966).

Archivo de Pablo Lejarraga (Biblioteca Marasso, Bahía Blanca, período consultado 1939-1966).

Archivo General de la Guerra Civil Española de Salamanca. (Período consultado 19361975)

Autobiografía de Nicolás Sánchez Albornoz: Cárceles y exilios. Barcelona: Anagrama, 2012.

Boletín Oficial del Estado del Gobierno de España. (Período consultado 1956-1966).

Diario El Atlántico (Bahía Blanca, período consultado 1956-1966).

Diario La Nueva Provincia (Bahía Blanca, período consultado 1956-1966).

Revista Cuadernos del Sur. (Bahía Blanca, Biblioteca Arturo Marasso, período consultado 1956-1966).

Revista Cursos y Conferencias. (Bahía Blanca, Biblioteca Arturo Marasso, período consultado 1956-1960).

\section{Referencias bibliográficas}

CERNADAS, Mabel (dir.) (2006). Universidad Nacional del Sur. 1956-2006. Bahía Blanca: EdiUNS.

DE MARCO, Miguel Ángel (2015). Universitarios rosarinos en la recepción de exiliados republicanos españoles. El decanato de Cortés Plá, 1934-1943. Universidad del Salvador; Revista Época de Historia; 11; 6-2015; 41-70.

DEVÉS VALDÉS, Eduardo (2014). Redes Intelectuales en América Latina. Chile: Colección Idea.

DÍAZ LABAJO, Arantxa (2004). Los profesores universitarios en el exilio republicano español en Argentina, una aproximación a través de las fuentes del AGGC. Ponencia presentada en el IV Simposio de Historia Actual, Logroño.

(2010). De cómo ingresar en un país: redes migratorias y mediadores en el exilio de los médicos republicanos en Argentina. En 200 años de Iberoamérica (18102010): Congreso Internacional: Actas del XIV Encuentro de Latinoamericanistas Españoles, Santiago de Compostela.

FERNANDEZ STACCO, Edgardo. (2009). Abandono a la contemplación: apuntes para la historia de la Universidad Nacional del Sur. Buenos Aires: Editorial Universitaria Rioplatense.

FIORUCCI, Flavia (2001). El antiperonismo intelectual: de la guerra ideológica a la guerra espiritual, Consultado en mayo de 2019 en http://lasa.international.pitt.edu/Lasa2001/FiorucciFlavia.pdf (2011), Intelectuales y peronismo. 1945-1955. Buenos Aires: Editorial Biblos. 
FREDERIC, Sabina, GRACIANO, Osvaldo y SOPRANO, German (Coords.) (2010), El Estado argentino y las profesiones liberales, académicas y armadas. Rosario: Prohistoria.

GROPPO, Bruno (2002). Los exilios europeos en el siglo XX. En: Yankelevich, P (Coord.) México, país refugio. La experiencia de los exilios en el siglo XX. México: Plaza y Valdés Editores

GUARDIOLA PUBLINS, José. (1992), Historia de los españoles en Bahía Blanca, Bahía Blanca: Editorial Encestando SRL

JENSEN, Silvina y LASTRA Soledad (2015), El problema de las escalas en el campo de estudio de los exilios políticos argentinos recientes, Avances del Cesor, $\mathrm{N}^{\circ} 12$, Primer semestre 2015.

LAMANA, Manuel (1960). La novela de posguerra. Bahía Blanca: Revista Cuadernos del Sur.

LIDA, Miranda (2018). La Fundación Rockefeller entre España y la Argentina. El caso de Claudio Sánchez Albornoz. Nueva York: Congreso; 4th International Conference on the Historical links between Spain and North America.

LOPEZ PASCUAL, Juliana, (2014), Representaciones, prácticas y tensiones en la institucionalización de las actividades culturales. Bahía blanca, 1940 - 1969, [Tesis doctoral inédita], Universidad Nacional del Sur.

RAMELLA, Franco. (1995). Por un uso fuerte del concepto de red en los estudios migratorios. En Bjerg, M. y Otero, H. Inmigración y redes sociales en la Argentina moderna, Tandil: Cemla-IEHS.

REVEL, Jacques. (1996), Jeux d'échelles. La micro-analyse à l'experience, Paris: Seuil/Gallimard.

RONIGER, Luis (2014), Destierro y exilio en América Latina: nuevos estudios y avances teóricos. Buenos Aires;Eudeba.

ORBE, Patricia (2007). La política y lo político en torno a la comunidad universitaria bahiense (1956-1976), Estudio de grupos, ideologías y producción de discursos, Mímeo [Tesis doctoral inédita], Universidad Nacional del Sur.

SANTILLI, Daniel. (2003). Representación gráfica de redes sociales: Un método de obtención y un ejemplo histórico. Mundo Agrario, vol. 3, $\mathrm{n}^{\circ} 6$.

SCHWARTZSTEIN, Dora (2001). Entre Franco y Perón: memoria e identidad del exilio republicano español en argentina. Barcelona: Critica.

SERNA, Justo y PONS, Anaclet (2003). En su lugar. Una reflexión sobre la historia local y el microanálisis. Toluca: UAEM. Pp 35-56.

SUREDA, Marqués Solomó. (2008). Sobre l'exili del magisteri republicà (1936-39). Reflexions y suggeriments. Educació i Història. Revista d'història de l'educació, $\mathrm{N}^{\circ} 12$.

ZAID, Gabriel (1990). Intelectuales. Revista Vuelta, número 168, noviembre de 1990.

Artigo recebido em 20 de agosto de 2019.

Aprovado em 23 de outubro de 2019. 